\title{
The CRAFFT test was accurate for screening for substance abuse among adolescent clinic patients
}

\author{
Knight JR, Sherritt L, Shrier LA, et al. Validity of the CRAFFT substance abuse screening test among adolescent clinic
} patients. Arch Pediatr Adolesc Med 2002;156:607-14.

\section{QUESTION: What is the accuracy of the CRAFFT test in screening for substance abuse among adolescents in a hospital based clinic?}

Sources of funding: National Institute on Alcohol Abuse and Alcoholism; Substance Abuse and Mental Health Services Administration; Rober Wood Johnson Foundation.

CRAFFT median score was 1 (range 0-6). A CRAFFT score of $\geq 2$ was optimal for identifying any problem, any disorder, and dependence (table 2). Validity of the CRAFFT test was not affected by age, sex, or race. psychiatric diagnostic interview.

\section{Setting}

A large, hospital based adolescent clinic in Boston, Massachusetts, USA.

\section{Participants}

538 adolescents between the ages of 14 and 18 years (68\% girls) attending the clinic for routine medical care. Exclusion criteria were inability to read or understand English, or acute medical or psychiatric problems.

\section{Description of test and diagnostic standards}

The 6 item CRAFFT test (table 1) was administered verbally and the responses to the 6 yes/no questions were recorded. 2 scales were administered concurrently for criterion validity. The first diagnostic standard was the 17 item Substance Use/Abuse Scale from the Problem Oriented Screening Instrument for Teenagers (POSIT), which assesses substance related problems and risks. The second diagnostic standard was the Adolescent Diagnostic Interview (ADI), which yields alcohol and drug related diagnoses according to the Diagnostic and Statistical Manual of Mental Disorders, 4th edition.

\section{Main outcome measures}

Receiver operating characteristic (ROC) curve areas, sensitivity, specificity, and likelihood ratios (LRs).

\section{Main results}

Participants were divided into 5 mutually exclusive diagnostic groups for substance use during the past 12 months based on the diagnostic standards: no use (50\%), occasional use (23\%), problem use (11\%), abuse $(9 \%)$, and dependence (7\%). The ROC curve areas for CRAFFT were high for all screening categories (any problem = 0.92 , any diagnosis $=0.90$, and dependence $=0.93$ ). The

\section{Table 1. The CRAFFT questions.}

C - Have you ever ridden in a car driven by someone (including yourself) who was"high" or had been using alcohol or drugs?

$\mathbf{R}$ - Do you ever use alcohol or drugs to relax, feel better about yourself, or fit in?

A - Do you ever use alcohol or drugs while you are by yourself, alone?

F - Do you ever forget things you did while using alcohol or drugs?

F - Do your family or friends ever tell you that you should cut down on your drinking or drug use?

$\mathbf{T}$ - Have you ever gotten into trouble while you were using alcohol or drugs?

\section{Conclusion}

The CRAFFT test was accurate for screening for substance abuse among adolescent clinic patients.
Table 2. Diagnostic characteristics for the CRAFFT test (cut point score $\geq 2$ ) in screening for substance abuse among adolescents*

\begin{tabular}{lllll} 
Substance use category & $\begin{array}{l}\text { Sensitivity } \\
(95 \% \text { CI) }\end{array}$ & $\begin{array}{l}\text { Specificity } \\
\text { (CI) }\end{array}$ & +LR & - LR \\
$\begin{array}{c}\text { Any problem (problem use, } \\
\text { abuse, or dependence) }\end{array}$ & $76 \%(68$ to 83$)$ & $94 \%(92$ to 96$)$ & 12.97 & 0.26 \\
\hline $\begin{array}{c}\text { Any diagnosis (abuse or } \\
\text { dependence) }\end{array}$ & $80 \%(72$ to 89$)$ & $86 \%(83$ to 89$)$ & 5.85 & 0.23 \\
\hline Dependence & $92 \%(82$ to 100$)$ & $80 \%(77$ to 83$)$ & 4.65 & 0.10
\end{tabular}

*Diagnostic terms defined in glossary. Likelihood ratios (LRs) were provided by the author

\section{COMMENTARY}

Screening tools, such as CAGE and the Alcohol Use Disorder Identification Test, have been primarily developed to detect substance abuse in adults. They may be less useful in young people, where patterns of use differ from those of adults. In the CRAFFT test, Knight $e t$ al present an exciting new screening tool that is easy to use, addresses both alcohol and drug use, and appears to be effective in screening adolescents. However, the investigators have relied on the participants accurately reporting their behaviour in response to both the screening tool and the diagnostic standards. This is a common problem with tools for substance misuse. The use of objective measures, such as urine testing, could reduce uncertainty in detection, but they are problematic in their own right. The pragmatic solution is further testing of CRAFFT, particularly in low prevalence populations. Successful validation across a spectrum of populations will increase confidence in this test. Developing a screening tool is simply the first step in any programme. Innovative delivery strategies need to be considered to enhance uptake of a test. Paper based tests, or verbal administration by authority figures, may adversely influence responses. Using touch screen computers in office waiting rooms or text messaging via cell phones may be sufficiently novel, but case finding will only be useful if health workers are willing or are able to act on the information. ${ }^{1}$ This is the substantive issue: there is little point in screening if there is no follow up interview, or if treatments are not available. A positive screening test simply indicates the need for further testing, preferably by someone skilled in the field. If the follow up interview is positive, then treatment may be required.

Knight $e t$ al point out that most inpatient treatment programmes are for adults. Even brief interventions that seem effective in adults ${ }^{2}$ may be less likely to be effective in young people, as these interventions tend to employ authority figures to enhance their message. Investing in routine screening for substance abuse must occur in conjunction with investment in appropriate treatment services.

Andrew Jull, RN, MA Research Fellow, Clinical Trials Research Unit University of Auckland Auckland, New Zealand

1 Whooley MA, Stone B, Soghikian K. Randomized trial of case-finding for depression in elderly primary care patients. J Gen Intern Med 2000;15:293-300.

2 D'Onofrio G, Degutis LC. Preventive care in the emergency department: screening and brief intervention for alcohol problems in the emergency department: a systematic review. Acad Emerg Med 2002;9:627-38. 